\title{
Characteristics of milk fever and mastitis following different milking method and preventive calcium injection performed during the colostrum period in dairy cattle
}

\author{
Ryounghoon Jeon* \\ College of Veterinary Medicine, Gyeongsang National University, Jinju 52828, Korea
}

Received July 30, 2020

Revised August 2, 2020

Accepted August 3, 2020

\section{*Correspondence}

Ryounghoon Jeon

E-mail: ryounghoonjeon@gmail.com

ORCID

https://orcid.org/0000-0003-3174-1197

\begin{abstract}
The milk fever and mastitis that occur during the colostrum period in dairy cattle cause great damage in the dairy industry by causing a rapid decline in the cattle's health and decreasing milk production. In order to prevent this, gradual milking $(\mathrm{GM})$, calcium injection with gradual milking (CG), and calcium injection with complete milking (CC) methods are used. However, differences in effectiveness between these methods have not been established. Therefore, this study was conducted to determine the effects of each preventive method on milk fever and mastitis. The results of this study showed that while there was a significant negative correlation of GM with milk fever and mastitis $(r=-0.657, p<0.05)$, there was no correlation of CG and CC with milk fever and mastitis. The incidence of milk fever was significantly lower in CG and CC than in GM $(p<0.05)$ but no differences in the incidence of mastitis were observed between the three groups. No significant differences in the rate of recovery from milk fever and mastitis were observed between the three groups. The recurrence rate of milk fever was significantly higher in CG and CC than in GM $(p<0.05)$, though no differences in the recurrence rate of mastitis were observed. This study showed an inverse relationship between the incidence rates of milk fever and mastitis when calcium injection was not used during the colostrum period. When calcium injections were used, the incidence of milk fever was reduced without affecting the incidence of mastitis regardless of the milking method, but the recurrence rate of milk fever was increased. The results of this study would be useful for controlling blood calcium concentrations and establishing efficient milking strategy in order to effectively prevent milk fever and mastitis in dairy cattle during the colostrum period.
\end{abstract}

Keywords: calcium injection, colostrum period, mastitis, milk fever, milking method

\section{INTRODUCTION}

The colostrum period is usually a 1 - to 2 -week period of rapid physiological changes during parturition. Failure to optimize the cattle's body for milk production during this period exposes the cattle to milk fever and mastitis, which significantly decrease productivity of dairy cattle. Therefore, the prevention of milk fever and mastitis is a big part of colostrum-period management (DeGaris and Lean, 2008; Down et al., 2016). 
Since the calcium content of colostrum is greater than that of subsequent milk, milk fever is a typical metabolic disease in dairy cattle caused by postparturient hypocalcemia within 2-3 days (McGrath et al., 2016; Seo et al., 2018). Although clinical manifestations of milk fever showed ablactation, decreased appetite, agitation, and orthostatic hypotension, immediate intravenous injection of calcium gluconate following early diagnosis could quickly restore blood calcium concentrations and relieving the clinical manifestations with high recovery rates (Thilsing-Hansen et al., 2002). However, if milk fever is not properly corrected in time, these manifestations deteriorate rapidly and could lead to coma, weakened pulse, necrosis of the sciatic nerve and fibular nerve secondary to limb stiffness, and, in the worst cases, death (DeGaris and Lean, 2008). Limiting calcium consumption during late dry period, late gestation period with non-lactating, or using preventive measures such as Vitamin D3 injections could mitigate the impact caused by rapid changes in the blood calcium concentration during the transition from pregnancy to the colostrum period (Sørensen et al., 2002).

Mastitis during the colostrum period is usually caused by improper milking after parturition. Mastitis could decrease or halt milk production in dairy cattle making it difficult to transfer sufficient immunity to the calf through colostrum (Sharma et al., 2012; Seo et al., 2018). Furthermore, the treatment of mastitis not only incurs additional cost and labor but also the use of antibiotics that decreases dairy cattle productivity by shortening the financially-viable lactation period (Nam et al., 2009; Ruegg, 2017). In the worst cases, the cattle lose financial value with extended mastitis treatment and might even get slaughtered. Therefore, mastitis is a disease that must be prevented in order to improve cattle productivity, longevity, and farm competitiveness.

Milking directly affects the amount of residual milk and/ or calcium necessary for milk production. Therefore, milking should be considered as a method of prevention of milk fever and mastitis during colostrum period (DeGaris and Lean, 2008; Gomes and Henriques, 2016). Gradual milking is most commonly used in farms as it can be easily followed in addition to existing milking process without any additional labor or medication and also this method directly prevents mastitis and milk fever by lessening the impact caused by changes in calcium metabolism (Horst et al., 1997).

Since the milk production ability and calcium metabolism differ for each cow and the milking is dependent on the performers' subjective senses and experiences, it is difficult to accurately carry out milking of each cow and maintain residual milk volumes with consistency. Failure to provide appropriate milking levels can cause milk fever and mastitis (Thilsing-Hansen et al., 2002; Down et al., 2016). Therefore, some farms use a combination of calcium injections after parturition to maintain blood calcium concentrations to prevent milk fever and/or complete milking to prevent mastitis by minimizing residual colostrum in the udder. However, the correlation between the incidence of milk fever and mastitis and these preventive methods is not clear and the injected calcium can affect various organs and tissues in body directly or indirectly. Therefore, the cattle's which receive calcium treatments needs to be carefully monitored (DeGaris and Lean, 2008).

Here, we studied the correlation, incidence, recovery rate, and recurrence rate of milk fever and mastitis to reveal the effects of milking method and preventive calcium injection on these two diseases during the colostrum period.

\section{MATERIALS AND METHODS}

\section{Animal information used in the study}

This study used data from 2860 Holstein cattle that gave birth between March 2014 and February 2019 at 15 farms in the eastern region of Gyeongsangbuk-do, South Korea. All farms maintained their ownership and location, management systems including reproductive programs, milking methods, and feeding during the duration of the study.

\section{Diagnosis and treatment of milk fever and mastitis}

Milk fever was diagnosed with clinical manifestations such as milk volume reduction, decreased appetite, excessive agitation, teeth grinding, gait disturbances, hypothermia, and limb stiffness during a period of 2 weeks following parturition. Calcium gluconate was administered through the external jugular vein for treatment of milk fever (DeGaris and Lean, 2008). Full recovery was defined as restoration of normal gait and appetite following treatment and milk production 
restoration to the pre-milk-fever level. Mastitis was diagnosed through clinical presentations such as milk volume reduction, hyperthermic edema, and pain, along with a positive result on the California mastitis test (CMT). For mastitis treatment, an antibiotic susceptibility test was performed to select appropriate antibiotic, and antibiotic ointment was administered within the udder. The resolution of clinical manifestation, negative CMT, and restoration of milk production to the pre-mastitis level was used to determine recovery from mastitis.

\section{Preventives and analysis items of milk fever and mastitis}

Based on the milking method and preventive calcium injection (PCI) performed during the colostrum period to prevent milk fever and mastitis, each farm were divided into only gradual milking group (GM), PCI with gradual milking group (CG) and PCI with complete milking group (CC). PCI was performed right after parturition, same as it is done in the milk fever treatment method. The data were collected from the period post-parturition to production of commercial milk based on passing the alcohol test and somatic cell scores on the crude milk. After recovery from each disease, the recurrence of an identical disease within the colostrum period was defined as recurrence. The analysis categories were correlation of milk fever and mastitis, incidence, recovery rate, and recurrence rate in each disease.

\section{Statistical analysis}

The characteristics of milk fever and mastitis incidence based on the milking method and PCI during the colostrum period were analyzed using Pearson's correlation coefficient and the ANOVA test, followed by the GamesHowell post-hoc test performed on Prism 7 (GraphPad Software, CA, USA). The threshold for statistical significance was set at $p<0.05$ and data are presented as mean \pm SD.

\section{RESULTS AND DISCUSSION}

Colostrum period is a period of rapid transition of the maternal physiology from pregnancy and parturition to lactation. Dairy cattle that cannot adapt to these changes are prone to milk fever and mastitis. This study was conducted to help establish a preventive strategy by identifying the diseases' incidence characteristics based on the milking method and PCI performed during the colostrum period as preventive measures.

With the exception of rapid decrease or halt in milk production, milk fever and mastitis during the colostrum period have different clinical manifestations and can affect various organs or tissues (Horst et al., 1997; Gomes and Henriques, 2016). However, both diseases are correlated to milking. Using this correlation, GM, which gradually increases milking level from delivery to complete milking, can be used to prevent both diseases. Since GM is easily applicable to general milking procedures in most dairy farms, it is widely used. This study showed that GM had a significant inverse correlation with milk fever and mastitis $(r=-0.657, p<0.05)$ (Fig. 1). This result is in line with the previous report that an excessive amount of residual milk in the udder secondary to insufficient milking causes an abnormal pressure to build up within the udder and predisposes it to mastitis (Down et al., 2016).
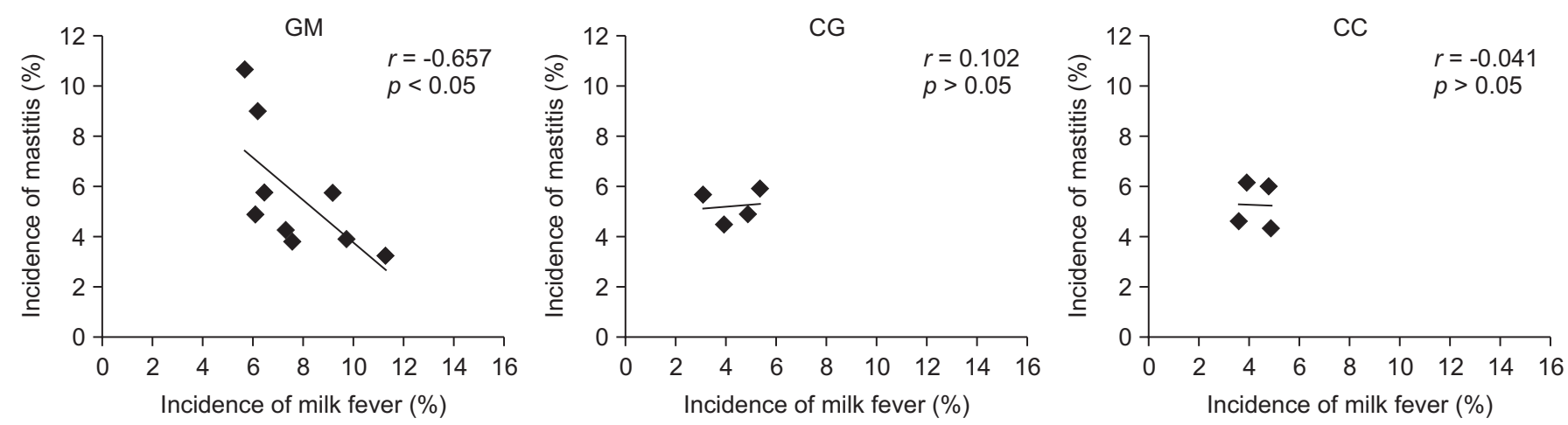

Fig. 1. Correlation between incidence of milk fever and mastitis following different milking methods and preventive calcium injections performed during the colostrum period in dairy cattle. Pearson's correlation $(r)$ was used to analyze correlation between milk fever and mastitis. GM: gradual milking group, CG: calcium injection with gradual milking group, CC: calcium injection with complete milking group. 
Alternatively, excessive milking results in rapid loss of calcium which leads to low blood calcium concentration predisposes the cow to milk fever (DeGaris and Lean, 2008). These results were similar to the results reported in preceding studies. Interestingly, the GM group showed diverse milk fever and mastitis incidences between 5.7$11.3 \%$ and $3.2-10.6 \%$, respectively. This result is likely to be secondary to the differing subjective standards and experiences in milking personnel, which lead to different residual milk levels and calcium losses in dairy cattle from different farms (Table 1). Based on these results, it is possible that the unclear effects of milking method on milk fever in previous studies were due to different subjective milking levels (Horst et al., 1997). Therefore, achieving satisfactory milking volume, residual volume, and blood calcium concentration through the milking method alone would be difficult.

Since consistent and appropriate milking is difficult and blood calcium concentration can be relatively easily corrected through exogenous administration, some farms use a modified strategy where calcium injection is first administered to prevent milk fever, and mastitis is prevented by regulating or not regulating the milking levels (Deb et al., 2013; Hernández-Castellano et al., 2020). In this study, the modified strategies were divided into PCI with gradually milking group (CG) and PCI with complete milking group (CC). The results showed that unlike GM, CG, and CC, which include PCI, did not correlate with milk fever and mastitis incidences (Fig. 1). In case of the incidence of milk fever, since blood calcium concentration directly affects incidence and recovery, CG and CC

Table 1. Incidence of milk fever and mastitis following different milking methods and preventive calcium injections performed during the colostrum period in dairy cattle

\begin{tabular}{|c|c|c|c|}
\hline \multirow{2}{*}{ Group } & \multirow{2}{*}{$\begin{array}{c}\text { Total number of } \\
\text { parturitions }\end{array}$} & \multicolumn{2}{|c|}{ Number of cases (\%) } \\
\hline & & Milk fever & Mastitis \\
\hline GM & 1390 & $\begin{array}{c}107 \\
(7.7 \pm 1.8)\end{array}$ & $\begin{array}{c}78 \\
(5.7 \pm 2.4)\end{array}$ \\
\hline$C G$ & 744 & $\begin{array}{c}32 \\
\left(4.5 \pm 1.1^{*}\right)\end{array}$ & $\begin{array}{c}40 \\
(4.9 \pm 1.2)\end{array}$ \\
\hline $\mathrm{CC}$ & 726 & $\begin{array}{c}29 \\
\left(4.2 \pm 0.8^{*}\right)\end{array}$ & $\begin{array}{c}38 \\
(5.3 \pm 1.0)\end{array}$ \\
\hline
\end{tabular}

GM, gradual milking group; CG, calcium injection with gradual milking group; CC, calcium injection with complete milking group. Data were expressed by mean $\pm \mathrm{SD} .{ }^{*} p<0.05$, designating significantly different values compared with GM group. showed a significantly decreased incidence of milk fever $(p<0.05)$ compared to GM (Table 1). It can be concluded that no differences in the incidence of milk fever was observed between CG and CC since calcium supplied by PCI sufficiently restored body calcium level which lost through milk production and milking (DeGaris and Lean, 2008). On the other hand, no differences in the incidence of mastitis were observed between GM, CG, and CC. It can be concluded that milking method in GM is effective for mastitis prevention and blood calcium concentration is far from being a cause of mastitis (Ruegg, 2017). Although CC performs complete milking, there was the consistent incidence of mastitis. This could be due to multiple factors that causing mastitis including residual milk volume, milking equipment, parity and living environment that promote the growth of mastitis-causing microorganisms (Nam et al., 2009; Sharma et al., 2012), however, further investigations are needed to determine the exact reason and to prevent mastitis.

Milk fever and mastitis arising during the colostrum period showed recovery rates of $91.6 \%$ and $85.2 \%$, respectively (Fig. 2). The recovery rates for both diseases showed no difference based on the milking method and calcium injection. Since hypocalcemia was corrected in cases of milk fever, the majority of subjects were treated successfully using methods similar to those used in previous studies (Sørensen et al., 2002; DeGaris and Lean, 2008). Since mastitis can be caused by different factors and dif-

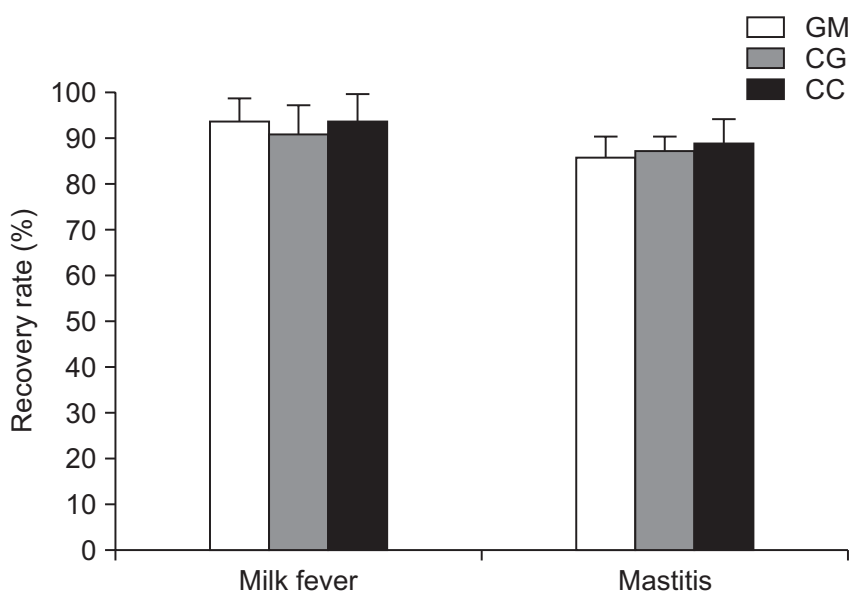

Fig. 2. Recovery rate of milk fever and mastitis following different milking methods and preventive calcium injections performed during the colostrum period in dairy cattle. GM: gradual milking group, CG: calcium injection with gradual milking group, CC: calcium injection with complete milking group. Data were expressed by mean \pm SD. 


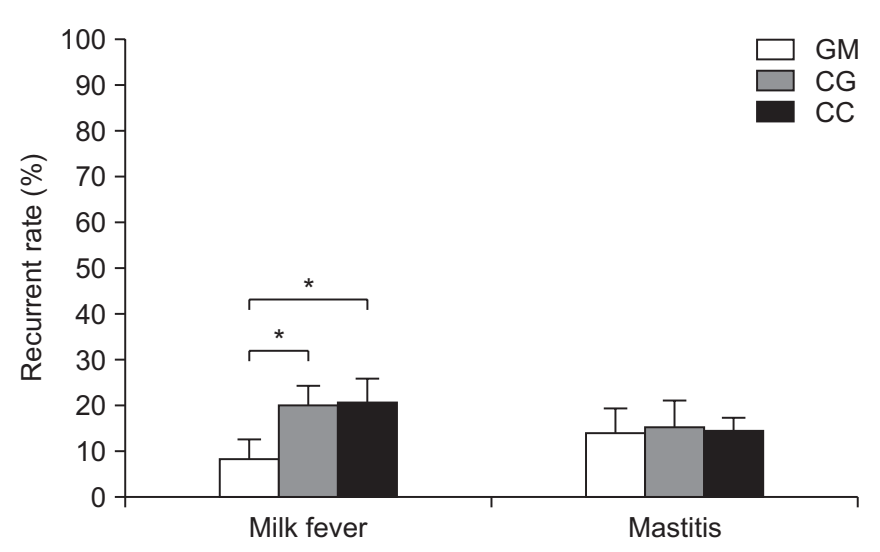

Fig. 3. Recurrent rate of milk fever and mastitis following different milking methods and preventive calcium injections performed during the colostrum period in dairy cattle. GM: gradual milking group, CG: calcium injection with gradual milking group, CC: calcium injection with complete milking group. Data were expressed by mean $\pm \mathrm{SD}$. ${ }^{*} p<0.05$, designating significantly different values compared with GM group.

ferent pathogens with different antibiotic susceptibilities, the recovery rate is lower than that of milk fever (Nam et al., 2009; Deb et al., 2013).

Due to the intrinsic consumption of calcium in dairy cattle during the lactation period, it is impossible to eliminate the causes of milk fever and mastitis, recurrence of each disease should be clearly determined to establish an effective preventive strategy (Jamali et al., 2018; Jeon and Rho, 2019). Interestingly, this study showed milk fever recurrence rates of $8.5 \%, 20.1 \%$ and $22.5 \%$ in GM, CG and CC respectively. Milk fever recurrence was significantly higher with PCI regardless of milking method $(p<0.05)$ (Fig. 3). This result is the first of its kind to demonstrate that PCI during the colostrum period increases milk fever recurrence. Based on a previous study that reported successful prevention of milk fever by optimizing the calcium metabolism in dairy cattle by limiting calcium intake in late dry period, recovery of milk fever in CG and CC by temporal exogenous calcium treatment leads to failure in proper stimulation of postpartum hypocalcemia and obtain physiology optimal for milk production resulting in higher recurrence of milk fever (Sørensen et al., 2002; Jeon and Rho, 2019; Hernández-Castellano et al., 2020).

Recurrences of mastitis were $13.9 \%, 15.1 \%$ and $14.5 \%$ in GM, CG and CC, and mastitis recurrence did not differ based on the milking method or calcium injection. As stated previously, it can be concluded that mastitis is independent from blood calcium concentration and that the milking method in GM alone was sufficient to prevent mastitis.

Since only few farms used CG and CC and this study focused on colostrum period, there were limitations in revealing the characteristics of milk fever and mastitis. Further studies should recruit large CG and CC groups and the investigation should be extended to lactation period and dry period.

\section{CONCLUSION}

Without preventive calcium injection, milk fever and mastitis were inversely correlated during the colostrum period. Preventive calcium injections effectively prevented milk fever, however, recurrence of milk fever increased. These results could help establish effective strategies to prevent both diseases. In further studies, the pathophysiology of milk fever and mastitis should be clearly determined in order to minimize milk fever and mastitis as well as recurrent milk fever that consistently occurs despite the use of preventive methods.

\section{CONFLICSTS OF INTEREST}

No potential conflict of interest relevant to this article was reported.

\section{AUTHOR CONTRIBUTIONS}

\author{
Conceptualization: RJ \\ Data curation: RJ \\ Formal analysis: RJ \\ Funding acquisition: RJ \\ Investigation: RJ \\ Methodology: RJ \\ Project administration: RJ \\ Resources: RJ \\ Software: RJ \\ Supervision: RJ \\ Validation: RJ \\ Visualization: RJ \\ Writing - original draft: RJ \\ Writing - review \& editing: RJ
}




\section{AUTHOR'S POSITION AND ORCID NO.}

R Jeon, Senior Researcher, https://orcid.org/0000-0003-3174-1197

\section{REFERENCES}

Deb R, Kumar A, Chakraborty S, Verma AK, Tiwari R, Dhama K, Singh U, Kumar S. 2013. Trends in diagnosis and control of bovine mastitis: a review. Pak. J. Biol. Sci. 16:1653-1661.

DeGaris PJ and Lean IJ. 2008. Milk fever in dairy cows: a review of pathophysiology and control principles. Vet. J. 176:58-69.

Down PM, Bradley AJ, Breen JE, Hudson CD, Green MJ. 2016. Current management practices and interventions prioritised as part of a nationwide mastitis control plan. Vet. Rec. 178:449.

Gomes F and Henriques M. 2016. Control of bovine mastitis: old and recent therapeutic approaches. Curr. Microbiol. 72:377-382.

Hernández-Castellano LE, Hernandez LL, Bruckmaier RM. 2020. Review: endocrine pathways to regulate calcium homeostasis around parturition and the prevention of hypocalcemia in periparturient dairy cows. Animal 14:330-338.

Horst RL, Goff JP, Reinhardt TA, Buxton DR. 1997. Strategies for preventing milk fever in dairy cattle. J. Dairy Sci. 80:12691280.
Jamali H, Barkema HW, Jacques M, Lavallée-Bourget EM, Malouin F, Saini V, Stryhn H, Dufour S. 2018. Invited review: incidence, risk factors, and effects of clinical mastitis recurrence in dairy cows. J. Dairy Sci. 101:4729-4746.

Jeon RH and Rho GJ. 2019. Incidence analysis of recurrent milk fever in Korean domestic dairy cattle. J. Anim. Reprod. Biotechnol. 34:30-34.

McGrath BA, Fox PF, McSweeney PLH, Kelly AL. 2016. Composition and properties of bovine colostrum: a review. Dairy Sci. Technol. 96:133-158.

Nam HM, Lim SK, Kang HM, Kim JM, Moon JS, Jang KC, Kim JM, Joo YS, Jung SC. 2009. Prevalence and antimicrobial susceptibility of gram-negative bacteria isolated from bovine mastitis between 2003 and 2008 in Korea. J. Dairy Sci. 92:2020-2026.

Ruegg PL. 2017. A 100-year review: mastitis detection, management, and prevention. J. Dairy Sci. 100:10381-10397.

Seo SA, Seo HR, Heo YT. 2018. Effective components of bovine colostrum and its applications. J. Emb. Trans. 33:159-168.

Sharma N, Rho GJ, Hong YH, Kang TY, Lee HK, Hur TY, Jeong DK. 2012. Bovine mastitis: an Asian perspective. Asian J. Anim. Vet. Adv. 7:454-476.

Sørensen JT, Østergaard S, Houe H, Hindhede J. 2002. Expert opinions of strategies for milk fever control. Prev. Vet. Med. 55:69-78.

Thilsing-Hansen T, Jørgensen RJ, Østergaard S. 2002. Milk fever control principles: a review. Acta Vet. Scand. 43:1-19. 